\title{
The C677T Variant in the Methylenetetrahydrofolate Reductase Gene and Idiopathic Spontaneous Abortion in a Romanian Population Group
}

\author{
Radu A. POPP'*, Tania O. CRISAN ${ }^{1}$, Adrian P. TRIFA' ${ }^{1}$, Mariela S. \\ MILITARU', Ioana C. ROTAR ${ }^{2}$, Marius F. FARCAS ${ }^{1}$, Ioan V. POP' \\ ${ }^{1}$ „Iuliu Hatieganu” University of Medicine and Pharmacy, Medical Genetics Department, 6 Pasteur \\ Street, Cluj-Napoca, Romania; radupopp2001@yahoo.com (*corresponding author) \\ ${ }^{2}$ "Iuliu Hatieganu" University of Medicine and Pharmacy, Ist Obstetrics and Gynecology Department, 3-5 Clinicilor Street, Cluj-Napoca, Romania
}

\begin{abstract}
Spontaneous abortions (SA) are a major publichealth problem and a frequent pregnancyassociated disorder. Hereditary thrombophilia and hyperhomocysteinemia are considered to be important factors altering the placental circulation, the in utero development and the evolution of pregnancy. The MTHFR gene (methylenetetrahydrofolate reductase) exhibits an intensely studied polymorphism, C677T, that was repeatedly associated with hyperhomocysteinemia, increased thrombotic risk and was studied in relation with SA susceptibility. This study was aim to assessing the correlation of this polymorphism with idiopathic sporadic or recurrent SA in a Romanian population. In the case-control study, 131 patients with a history of SA and 135 women with no SA and at least one uneventful term delivery were included. The PCR-RFLP technique (Polymerase Chain Reaction-Restriction Fragment Length Polymorphism) was used to genotype the cases and controls and the results were analysed using the $\chi^{2}$ test. The present analysis indicates that the MTHFR 677TT homozygous genotype is positively associated with recurrent idiopathic SA (OR 2.493, 95\%CI 0.974, 6.379, p-value 0.06). This association was no longer observed in sporadic SA patients (OR 1.214,95\%CI 0.488, 3.017, p-value 0.814). In conclusion, the present study is consistent with previous reports which state that the presence of MTHFR $677 \mathrm{~T}$ variant in homozygous status could represent a genetic susceptibility factor for recurrent idiopathic SA. Moreover, this is the first attempt to investigate this correlation in a Romanian group and to offer epidemiological support in estimating the frequencies of some common genetic variants in the Romanian population.
\end{abstract}

Keywords: association, folates, homocysteine, polymorphism, pregnancy

\section{Introduction}

At present, reproductive failure is one of the major public health problems. In humans, the probability of conception during one menstrual cycle is approximated at a maximum of $40 \%$ (Kavalier $e t$ al., 2005). Moreover, 10$15 \%$ of clinically recognized pregnancies end in spontaneous abortion (SA). The causes of this can be fetal or maternal, anatomical, infectious, immunological or genetic, and in aproximately $50 \%$ of cases, despite all investigations, the causes cannot be determined. In this latter situation, the SA is declared idiopathic (Carp et al., 2004; Kavalier et al., 2005 Royal College of Obstetricians and Gynecologists, 2003).

Over the past years, emerging information has described that pregnancy-associated trombophilia could be a factor altering the normal evolution of pregnancy. $\mathrm{Nu}$ merous studies focus on the mechanism through which hyperhomocysteinemia, hereditary trombophilia (such as protein $\mathrm{C}$ or protein $\mathrm{S}$ deficiency, the factor $\mathrm{V}$ Leiden mutation, the prothrombin G20210A mutation) or combinations of these factors, could influence the normal in utero development and even play a role in spontaneous abortion etiology. Some authors suggest that as many as $60 \%$ of pregnancy losses could have been provoked by coagulation disorders (Bick and Hoppensteadt, 2005; Mitic et al., 2010). However, these conclusions are often inconsistent and results are contradictory (Altomare et al., 2007; Robertson et al., 2005; Rodger et al., 2010). Considering the subject of deep venous thrombosis, the most studied mutations in hereditary thrombophilia are the Leiden mutation, the G20210A mutation of prothrombin (factor II) and the variants of the MTHFR (methylenetetrahydrofolate reductase) gene. Also in relation with pregnancy and SA, the forementioned variants are most extensively investigated in association studies (Coulam et al., 2008; Kovalevsky et al., 2004). MTHFR is an extremely important enzyme in the homocysteine and folate metabolism which catalyses the production of 5-methyltetra hydrofolate. This compound is the methyl donor for the metabolisation of homocysteine to methionine and, thus, the reduction of plasma homocysteine levels (Reyes-Engel et al., 2002). Several variants of this gene can alter the activity of the MTHFR enzyme, the two best known of these being 
8

the MTHFR C677T and A1298C single nucleotide polymorphisms (SNP) (Frosst et al, 1995; Van der Put et al, 1998). Hyperhomocysteinemia is recognised as a thrombosis risk factor exherting its detrimental effects through diverse mechanisms (Brattstrom et al, 1998; Cetin et al., 2010; Nadir et al., 2007). The MTHFR C677T variant has already been correlated with high homocysteine and low folic acid levels in various populations and pathologies (Altomare et al., 2007; Bagheri et al., 2010; Gudnason et al., 1998; Guéant-Rodriguez et al., 2006).

The aim of the present study is to investigate the distribution of the MTHFR C677T polymorphism as a possible genetic risk factor for idiopathic SA in a Romanian population group.

\section{Materials and methods}

The present research was designed as an observational case-control study. Between March 2007 and December 2009 for examinations, genetic counseling or other investigations, 266 Caucasian women from the Romanian population were recruited from the patients visiting the office of the $\mathrm{II}^{\text {nd }}$ Genetic Investigations Laboratory, ClujNapoca, Romania. The case group consisted of 131 fertile age women with a history of first trimester SA (first 14 weeks of gestation), declared idiopathic after clinical and paraclinical investigations: ultrasonography, hormonal dosage, antiphospholipid antibodies dosage, TORCH serology, karyotype analysis. For the analysis of risk, the case group was further divided in two subgroups depending on the number of SA events: 46 cases with recurrent SA (at least $3 \mathrm{SA}$ ) and 85 cases with history of less than 3 SA. The control group was made of 135 women with at least one uncomplicated pregnancy and the birth of a healthy child, with no history of spontaneous abortion. The patients presenting associated comorbidities (vascular, hormonal, immunological, chromosomial pathologies, obesity or diabetes mellitus) were not included in the study. Tab. 1. Main parameters of spontaneous abortion (SA) cases and control volunteers

\begin{tabular}{ccc}
\hline & Cases & Controls \\
\hline Age in years (mean \pm standard deviation) & $31.19 \pm 5.22$ & $40.62 \pm 8.61$ \\
$\quad \begin{array}{c}\text { Number of abortions (mean } \\
\pm \text { standard deviation) }\end{array}$ & $2.40 \pm 1.25$ & 0 \\
$\begin{array}{c}\text { Number of uncomplicated pregnancies } \\
\text { Number of patients with recurrent } S A(\geq 3)\end{array}$ & 0 & $\geq 1$ \\
\hline
\end{tabular}

The participation in this study was voluntary and written informed consent was obtained from all participants upon inclusion. A set of general parameters of the study groups is presented in Tab. 1 .

For the genotype analysis, $5 \mathrm{ml}$ samples of peripheral blood were harvested on EDTA and stored at $4^{\circ} \mathrm{C}$ until DNA isolation. DNA was extracted out of white blood cells using Wizard Genomic DNA Purification Kit (Promega, MA, USA). The quantity and purity of the DNA samples were analysed using an Eppendorf photometer (Eppendorf, Germany). A DNA concentration of 50-100 $\mathrm{ng} / \mathrm{\mu l}$ was considered satisfactory for the analysis. The detection of the MTHFR C677T SNP was performed through the PCR-RFLP technique (polymerase chain reaction-restriction fragment length polymorphism) after the protocol described by Zhou-Cun et al. (2006), with some modifications. The following primers were used to amplify a 265 bp fragment containing the polymorphism: Fw 5'-CATCCCTATTGGCAG GTTAC-3' and Rev 5'-GACGGTGCGGTGAG AGTG-3'. The amplification took place in $25 \mu \mathrm{l}$ of reaction mix containing: 12,5 $\mu$ PCR Mix (recombinant Taq polymerase 0,05 IU/ $\mu \mathrm{l}$; $\mathrm{MgCl}_{2} 4 \mathrm{mM}$; dATP, dGTP, dCTP, dTTP at a concentration of $0,4 \mathrm{mM}$ each), $1 \mu \mathrm{l} \mathrm{BSA}$ solution (Bovine Serum Albumine) $2 \mathrm{mg} / \mathrm{ml}, 1 \mu \mathrm{l}$ of each primer solution (1.5 pmoles/ $\mu \mathrm{l}), 2 \mu \mathrm{l}$ of DNA sample and nuclease-free water until the final volume of $25 \mu \mathrm{l}$. The PCR consisted of an initial denaturation of 5 minutes at $94^{\circ} \mathrm{C}$ followed by 35 amplification cycles $\left(30\right.$ seconds $-94^{\circ} \mathrm{C}, 30$ seconds $-57^{\circ} \mathrm{C}$, 30 seconds $-72^{\circ} \mathrm{C}$ ) and a final elongation of 5 minutes at $72^{\circ} \mathrm{C}$. The 265 bp amplicon was subjected to overnight digestion at $37^{\circ} \mathrm{C}$ using the HinfI restriction enzyme, 2 units in $10 \mu \mathrm{l}$ of amplification product. The identification of restriction products was performed through horizontal electrophoresis in ethidium bromide stained 2\% agarose gels. The interpretation was made based on the length of restriction fragments as follows: homozygous genotype for the common $677 \mathrm{C}$ allele: $265 \mathrm{bp}$; heterozygous genotype: $265 \mathrm{bp}, 171 \mathrm{bp}$ and $94 \mathrm{bp}$; homozygous genotype for the variant $677 \mathrm{~T}$ allele: $171 \mathrm{bp}$ and $94 \mathrm{bp}$.

The genotypes were centralised in an Excel database and the statistical analysis was performed using GraphPad InStat 3.10 and SPSS 16.0 for Windows. Allele and genotype frequencies were compared using the $\chi^{2}$ test. The approximate risk is presented as Odds Ratios with 95\% Confidence Intervals. Results were considered statistically significant at $\mathrm{p}$-value $<0.05$.

Tab. 2. Allele and genotype frequencies for MTHFR C677T in spontaneous abortion (SA) cases and control volunteers

\begin{tabular}{|c|c|c|c|c|c|}
\hline & \multicolumn{2}{|c|}{ Aleles frequencies, no. (\%) } & \multicolumn{3}{|c|}{ Genotypes frequencies, no. (\%) } \\
\hline & $\begin{array}{c}\text { C allele } \\
\text { (common) }\end{array}$ & $\begin{array}{c}\text { T allele } \\
\text { (variant) }\end{array}$ & $677 \mathrm{CC}$ & 677CT & 677TT \\
\hline All SA cases $(n=131)$ & $166(63.35)$ & $96(36.64)$ & $53(40.45)$ & $60(45.8)$ & $18(13.74)$ \\
\hline Controls $(\mathrm{n}=135)$ & $188(69.62)$ & $82(30.37)$ & $65(48.14)$ & $58(42.96)$ & $12(8.88)$ \\
\hline Recurrent $S A(\geq 3 S A)(n=46)$ & $54(58.69)$ & $38(41.30)$ & $17(36.95)$ & $20(43.47)$ & $9(19.56)$ \\
\hline Sporadic SA $(<3$ SA $)(n=85)$ & $112(65.88)$ & $58(34.11)$ & $36(42.35)$ & $40(47.05)$ & $9(10.58)$ \\
\hline
\end{tabular}


Tab. 3. Risk analysis for spontaneous abortion (SA) compared to controls

\begin{tabular}{|c|c|c|c|c|}
\hline Model & Pathology & Odds ratio & p value & $95 \% \mathrm{CI}$ \\
\hline \multirow{3}{*}{$\begin{array}{c}\text { MTHFR C677T } \\
\mathrm{CT}+\mathrm{TT} \text { genotypes vs. CC genotype }\end{array}$} & All SA cases & 1.367 & 0.219 & $0.840,2.221$ \\
\hline & $\begin{array}{l}\text { Sporadic SA subgroup } \\
\qquad(<3 \mathrm{SA})\end{array}$ & 1.264 & 0.408 & $0.731,2.184$ \\
\hline & $\begin{array}{l}\text { Recurrent SA subgroup } \\
(\geq 3 \mathrm{SA})\end{array}$ & 1.584 & 0.230 & $0.796,3.150$ \\
\hline \multirow{3}{*}{$\begin{array}{c}\text { MTHFR C677T } \\
\text { TT genotype vs. CT+CC genotypes }\end{array}$} & All SA cases & 1.633 & 0.247 & $0.753,3.540$ \\
\hline & $\begin{array}{l}\text { Sporadic SA subgroup } \\
\qquad(<3 \mathrm{SA})\end{array}$ & 1.214 & 0.814 & $0.488,3.017$ \\
\hline & $\begin{array}{l}\text { Recurrent SA subgroup } \\
\qquad(\geq 3 \mathrm{SA})\end{array}$ & 2.493 & 0.06 & $0.974,6.379$ \\
\hline
\end{tabular}

\section{Results}

The allele frequencies and genotype distribution for the MTHFR C677T polymorphism does not signifficantly differ between cases and controls (data are presented in Tab. 2). The observed genotype frequencies were in Hardy-Weinberg equilibrium ( $p>0.05)$.

Association analyses have been conducted for all SA cases as well as for the two case subgroups described earlier compared to controls. The results of the comparative analyses are depicted in Tab. 3. $\chi^{2}$ test was used to test for two hypothetical risk models: the dominant model (the 677T variant is a risk factor in both homozygous and heterozygous status) and the recessive model (only the homozygous 677TT genotype is considered a risk factor).

These results suggest that the simple presence of the MTHFR 677T allele in the individual genotype does not represent a risk factor for idiopathic SA. The homozygous MTHFR 677TT genotype only in case of recurrent spontaneous abortions seems to increase the susceptibility to disease, with a statistical analysis very close to the significance level $(\mathrm{p}=0.06)$.

The same analysis performed by comparing the recurrent SA subgroup with the sporadic SA subgroup yielded unsignificant differences (CT + TT genotypes vs. CC genotype: OR 1.253; 95\%CI 0.599, 2.62; p 0.58 and TT genotype vs. CC + CT genotypes: OR 2.054; $95 \%$ CI 0.752, 5.607; p 0.186).

\section{Disscussion}

An earlier case-control study on 10 genes with possible trombophilic effect and SA risk (Goodman et al., 2006), shows that only 3 genotypes could be significantly correlated with the disorder, among which the homozygous MTHFR 677TT genotype was reported $(\mathrm{p}<0.04)$. This could also be declared as risk factor for recurrent SA by Coulam et al. (2008). In another approach, Sotiriadis et al. (2007) did not confirm that the 677T allele represents a risk factor for idiopathic pregnancy loss neither in homozygous nor in heterozygous status. The same study shows that the homozygous 677TT genotype does not follow a different distribution in patients with a history of at least 3 SA compared to patients with less then 3 SA. In the literature review by Bick and Hoppensteadt (2005), the functional variants of MTHFR are reported next to factor V Leiden, prothrombin G20210A and the 4G/5G polymorphism of the plasminogen activator gene (PAI-I) as common causes for recurrent spontaneous abortions. A sistematic review on thrombophilia and pregnancy (Robertson et al, 2005) based on 79 different studies shows that, upon stratification for thrombotic risk factors, the risk for early spontaneous abortion is significantly enhanced when hyperhomocysteinemia was present (OR 6.25, 95\%CI $1.37,28.42)$. The Guide of the Italian Society of Gynecology and Obstetrics (on the basis of 10 meta-analyses and reviews) states that there is not sufficient evidence to recommend some thrombophilia associated gene variants, including MTHFR C677T and A1298C polymorphisms, to be investigated in patients with idiopathic SA (Lussana et al., 2009). One study on placental vasculopathies and their correlation with the same MTHFR variants concludes that $\mathrm{C} 677 \mathrm{~T}$ is not significantly associated with placental vascular pathology and it cannot predict maternal hyperhomocysteinemia (Klai et al., 2011). However, the MTHFR 677TT genotype is identified as a high genetic risk factor for recurrent $S A$, together with the homozygous $5 \mathrm{G} / 5 \mathrm{G}$ polymorphism of the $P A I-1$ gene in a Turkish population (Yenicesu et al., 2009). In agreement with this and also with the present study's findings, the homozygous MTHFR 677TT genotype was found with an increased frequency in recurrent $S A$ patients in a Serbian population (Mitic et al., 2010).

\section{Conclusions}

The present this study represents the first association approach on MTHFR C677T and idiopathic SA, recurrent or sporadic, in the Romanian population. The present study has some limitations such as the relatively small number of recurrent $S A$ cases or the impossibility to determine maternal plasma levels of homocysteine and folate. However, the here presented data are concordant with other literature reports, which indicate that the homozygous MTHFR 677TT genotype is a possible risk factor for 
10

recurrent $S A$, though this is not observed in the case of sporadic SA patients. As previous literature suggests, this association is still subject of debate, probably due to other numerous genetic or environmental factors that could influence the etiopathogeny of SA. Nevertheless, the present study could represent a first step in the future analysis of other conditions related to this pathology in Romanians. Moreover, this study provides supportive information regarding the genetic epidemiology of certain gene variants in the Romanian population.

\section{Acknowledgements}

This study was supported by the 546/2007 research grant of the National Council of Universitary Scientific Research (CNCSIS), Romania.

\section{References}

Altomare I, Adler A, Aledort LM (2007). The 5, 10 methylene tetrahydrofolate reductase $\mathrm{C} 677 \mathrm{~T}$ mutation and risk of fetal loss: a case series and review of the literature. Thromb J 5:1721.

BagheriM,AbdiRadI,OmraniMD,NanbakhshF(2010).C677T and A1298C Mutations in the methylenetetrahydrofolate reductase gene in patients with recurrent abortion from the Iranian Azeri Turkish. Internat J Fert Ster 4(3):134-139.

Bick RL, Hoppensteadt D (2005). Recurrent miscarriage syndrome and infertility due to blood coagulation protein/ platelet defects: A review and update. Clin Appl Thromb Hemost 11:1-13.

Brattstrom L, Wilcken DE, OhrvikJ, Brudin L (1998). Common methylene tetrahydrofolate reductase gene mutation leads to hyperhomocysteinemia but not to vascular disease: the result of a metaanalysis. Circulation 98:2520-2526.

Carp HJA, Dirnfeld M, Dor J, Grudzinskas JG (2004). ART in recurrent miscarriage: preimplantation genetic diagnosis/ screening or surrogacy? Human Reproduct 19(7):15021505.

Cetin I, Berti C, Calabrese S (2010). Role of micronutrients in the peri conceptional period. Human Reproduct Update 16(1):80-95.

Coulam CB, Wallis D, Weinstein J, DasGupta DS, Jeyendran RS (2008). Comparison of thrombophilic gene mutations among patients experiencing recurrent miscarriage and Deep vein thrombosis. Am J Reprod Immunol 60:426-431.

Frosst P, Blom HJ, Milos R, Goyette P, Sheppard CA, Matthews RG, Boers GJ, Den Heijer M, Kluijtmans LA, Van Den Heuvel LP (1995). A candidate genetic risk factor for vascular disease: a common mutation in methylenetetrahydrofolate reductase. Nature Genetics 10(1):111-113.

Goodman CS, Coulam CB, Jeyendran RS, Acosta VA, Roussev R (2006). Which thrombophilic gene mutations are risk factors for recurrent pregnancy loss? Am J Reprod Immunol 56:230-236.
Gudnason V, Stansbie D, Scott J, Bowron A, Nicaud V, Humphries S (1998). C677T (thermolabile alanine/ valine) polymorphism in methylenetetrahydrofolate reductase $(M T H F R)$ : its frequency and impact on plasma homocysteine concentration in different European populations EARS group. Atherosclerosis 136:347-354.

Guéant-Rodriguez RM, Guéant JL, Debard R, Thirion S, Hong LX, Bronowicki JP, Namour F, Chabi NW, Sanni A, Anello G, Bosco P, Romano C, Amouzou E, Arrieta HR, Sanchez BE, Romano A, Herbeth B, Guilland JC, Mutchinick OM (2006). Prevalence of methylenetetrahydrofolate reductase $677 \mathrm{~T}$ and $1298 \mathrm{C}$ alleles and folate status: a comparative study in Mexican, West African, and European populations. Am J Clin Nutr 83:701-707.

Kavalier F (2005). Investigation of recurrent miscarriages. British Med J 331:121-122.

Klai S, Fekih-Mrissa N, El Housaini S, Kaabechi N, Nsiri B, Rachdi R, Gritli N (2011). Association of MTHFR A1298C polymorphism (but not of MTHFR C677T) with elevated homocysteine levels and placental vasculopathies. Blood Coag Fibrinolysis 22:374-378.

Kovalevsky G, Gracia CR, Berlin JA, Sammel MD, Barnhart KT (2004). Evaluation of the association between hereditary thrombophilias and recurrent pregnancy loss. Arch Intern Med 164(5):558-563.

Lussana F, Dentali F, Abbate R, d'Aloja E, D'Angelo A, De Stefano V, Faioni EM, Grandone E, Legnani C, Martinelli I, Simioni P, Tormene D (2009). Screening for thrombophilia and antithrombotic prophylaxis in pregnancy: Guidelines of the Italian Society for Haemostasis and Thrombosis (SISET). Thromb Res 124:19-25.

Mitic G, Kovac M, Povazan L, Magic Z, Djordjevic V, Salatic I, Mitic I, Novakov-Mikic A (2010). Inherited thrombophilia is associated with pregnancy losses that occur after $12^{\text {th }}$ gestational week in Serbian population. Clin Appl Thromb Hemost 16(4):435-439.

Nadir Y, Hoffman R, Brenner B (2007). Association of homocysteine, vitamin B12, folic acid, and MTHFR C677T in patients with a thrombotic event or recurrent fetal loss. Ann Hematol 86:35-40.

Reyes-Engel A, Muñoz E, Gaitan MJ, Fabre E, Gallo M, Dieguez JL, Ruiz M, Morell M (2002). Implications on human fertility of the $677 \mathrm{C} \rightarrow \mathrm{T}$ and $1298 \mathrm{~A} \rightarrow \mathrm{C}$ polymorphisms of the MTHFR gene: consequences of a possible genetic selection. Mol Hum Reprod 8(10):952-957.

Robertson L, Wu O, Langhorne P, Twaddle S, Clark P, Lowe GDO, Walker ID, Greaves M, Brenkel I, Regan L, Greer IA (2005). Thrombophilia in pregnancy: a systematic review. British J Haematol132:171-196.

Rodger MA, Betancourt MT, Clark P, Lindqvist PG, DizonTownson D, Said J, Seligsohn U, Carrier M, Salomon O, Greer IA (2010). The association of factor V Leiden and prothrombin gene mutation and placenta-mediated pregnancy complications: a systematic review and meta- 
analysis of prospective Cohort studies. PLoS Med 7(6):1-12.

Royal College of Obstetricians and Gynaecologists (2003). The investigation and treatment of couples with recurrent miscarriage. Guidline no.17:1-13.

Sotiriadis A, Vartholomatos G, Pavlou M, Kolaitis N, Dova L, Stefos T, Paraskevaidis E, Kalantaridou SN (2007). Combined thrombophilic mutations in wWomen with unexplained recurrent miscarriage. Am J Reprod Immunol 57:133-141.

Van Der Put NM, Gabreëls F, Stevens EM, Smeitink JA, Trijbels FJ, Eskes TK, Van Den Heuvel LP, Blom HJ (1998). A second common mutation in the methylenetetrahydrofolate reductase gene: an additional risk factor for neural-tube defects? J Am College Cardiol 32(2):353-359.
Yenicesu GI, Cetin M, Ozdemir O, Cetin A, Ozen F, Yenicesu C, Yildiz C, Kocak N (2009). A prospective case-control study analyzes 12 thrombophilic gene mutations in Turkish couples with recurrent pregnancy loss. Am J Reprod Immunol 63:126-136.

Zhou-Cun A, Yang Y, Zhang SZ, Li N, Zhang W (2007). Single nucleotide polymorphism C677T in the methylenetetrahydrofolate reductase gene might be a genetic risk factor for infertility for Chinese men with azoospermia or severe oligozoospermia. Asian J Androl 9:57-62. 